\title{
Serum concentration of matrix metalloproteinases and angiogenic factors in patients with venous leg ulcers
}

\author{
Paweł Kolano', Igor A. Bednarski², Marzena Kraska-Gacka³, Joanna Narbutt², Aleksandra Lesiak² \\ ${ }^{1}$ Department of General and Oncological Surgery, Tomaszów Health Center, Tomaszow Mazowiecki, Poland \\ ${ }^{2}$ Dermatology, Pediatric Dermatology and Oncology Clinic, Medical University of Lodz, Lodz, Poland \\ ${ }^{3}$ Department of Dermatology and Venereology, Medical University of Lodz, Lodz, Poland
}

Adv Dermatol Allergol 2021; XXXVIII (2): 230-234

DOI: https://doi.org/10.5114/ada.2021.106201

\begin{abstract}
Introduction: Leg ulcers are a frequently observed medical problem affecting 3-5\% of the general population over 65 years of age. The most common factor responsible for the development of leg ulcers is chronic venous insufficiency (CVI). It is believed that during the formation of an ulcer there are two processes occurring simultaneously, extracellular matrix (ECM) degradation and angiogenesis in which several proteins including matrix metalloproteinases, angiogenic and regulatory factors are engaged.

Aim: To determine the serum concentration of matrix metalloproteinase-1 (MMP-1), -9 (MMP-9), tissue inhibitors of metalloproteinases-1 (TIMP-1), angiogenin and vascular endothelial growth factor (VEGF) in patients suffering from venous leg ulcers and in the healthy control group.

Material and methods: The study group consisted of 71 Caucasians (39 patients, 32 controls). To evaluate the serum concentration of MMP-1, MMP-9, TIMP-1, VEGF and angiogenin, the ELISA technique was used.

Results: Mean MMP-1 and MMP-9 concentrations in the study group were $14.16 \pm 2.98$ and $12.45 \pm 3.85 \mathrm{ng} / \mathrm{ml}$, respectively, and in controls $6.08 \pm 2.51 \mathrm{ng} / \mathrm{ml}$ and $6.77 \pm 2.41 \mathrm{ng} / \mathrm{ml}$, respectively and both differences were statistically significant $(p<0.001)$. There was no significant difference between the study and the control group in TIMP-1 concentration. Mean VEGF and ANG concentrations in the study group were $589.3 \pm 346.2 \mathrm{pg} / \mathrm{ml}$ and $1802.0 \pm 415.7$ $\mathrm{pg} / \mathrm{ml}$, respectively, and in controls $220.3 \pm 110.4 \mathrm{pg} / \mathrm{ml}$ and $1229.0 \pm 337.7 \mathrm{pg} / \mathrm{ml}$, respectively and both differences were statistically significant $(p<0.001)$.

Conclusions: Lack of significant differences in the concentration of TIMP-1 between the control and the study group confirms that proteolysis is a hallmark of CVI, but increased concentration of VEGF and angiogenin in the study group compared to the control group shows that angiogenesis occurs simultaneously with ECM remodelling.

Key words: venous leg ulcers, cathepsin K.
\end{abstract}

\section{Introduction}

Leg ulcers are nowadays a frequently observed medical problem which affects approximately $3-5 \%$ of the general population over 65 years of age. The incidence of leg ulcers is tightly connected with demographic and environmental factors such as population aging, sedentary lifestyle, obesity and tobacco consumption, thus making leg ulcers one of the diseases of affluence. The most common factor responsible for the development of leg ulcers is vascular disorders, especially chronic venous insufficiency (CVI), manifesting as varicose veins, deep vein thrombosis and ulceration. CVI affects about $38 \%$ of men and 51\% of women in the Polish population [1] being responsible for about 65\% of all leg ulcer diagnoses [2]. It is believed that during the formation of an ulcer there are two processes occurring simultaneously, extracellular matrix (ECM) degradation and angiogenesis in which several proteins including matrix metalloproteinases, angiogenic and regulatory factors are engaged.

Extracellular matrix metalloproteinases (MMPs) are proteases which are catalysing the hydrolytic reaction of a peptide bond inside polypeptide chains [3]. MMPs belong to the superfamily of proteolytic enzymes containing the $\mathrm{Zn}^{2+}$ atom in their catalytic centre [4]. According to the cur-

Address for correspondence: Igor A. Bednarski MD, Dermatology, Paediatric Dermatology and Oncology Clinic, Medical University of Lodz, 1/5 Kniaziewicza St, 91-347 Lodz, Poland, phone/fax: +48 42251 61 92, e-mail: igorbednarskiv@gmail.com Received: 22.07.2019, accepted: 14.09.2019. 
rent literature, a total of 23 enzymes belong to the family of metalloproteinases, slightly differing in their quaternary structure, which are classified by their structure and substrate specificity [5]. Regardless of the classification, the typical feature of metalloproteinases is their function of remodelling and degradation of the extracellular matrix [5-7]. In terms of venous ulcer development it seems that major key players are MMP-1 and MMP-9. MMP-1 degrades type-I collagen that is the main component of the ECM as well as other collagen types - II, -III, -V and -IX [8, 9]. MMP-1 expression is strongly associated with the wound healing process in which it enables secondary epithelialization via migration of keratinocytes due to type-I collagen proteolysis [10]. Increased MMP-1 expression is also associated with worse prognosis in colorectal cancer [11], oesophageal cancer [12] or bladder cancer [13]. MMP-9 degrades collagen types -IV, - V, -XI and -XIV [14], and is usually expressed during the tissue remodelling process, inflammatory reactions or invasive tumour growth [15]. Some previous studies have shown that high levels of MMP-9 can delay ulceration in patients with diabetic foot, although the mechanism has not been clarified yet $[15,16]$. The activity of both metalloproteinases can be regulated by endogenous inhibitors, mainly $\alpha 2$-macroglobulin and tissue inhibitors of metalloproteinases (TIMP) [17]. TIMP-1 is able to block the activity of these metalloproteinases by forming coordination bonds with them in a stoichiometric ratio of $1: 1$, however, it shows particular affinity towards MMP-9 [18]. TIMP-1 is one of the critical regulators of the wound healing process by balancing the participation of metalloproteinases in ECM remodelling and inhibiting apoptosis of endothelial cells and platelets in the presence of proinflammatory cytokines [19].

As mentioned above, the second process happening concurrently with ECM degradation is angiogenesis which consists of several stages. Angiogenesis starts with increased permeability of blood vessels and the accumulation of MMPs in the ECM, leading to degradation of the basal membrane components and reorganization of the vessel walls, thus allowing the migration and proliferation of endothelial cells, which results in formation of new blood vessels within the ECM. It has been shown that the crucial role here is played by angiogenin and vascular endothelial growth factor (VEGF). Angiogenin (ANG) is the first discovered protein involved in the stimulation of tumour angiogenesis first described by Bert L. Vallee in 1985 [20]. ANG is one of the strongest factors stimulating the formation of blood vessels, however it is also participating in neuroprotective mechanisms, regeneration of damaged tissues and innate immunological response. Disruption of ANG levels are found in coronary heart disease, heart failure, diabetes and neurodegenerative diseases, e.g. amyotrophic lateral sclerosis (ALS) or Parkinson's disease (PD) [21]. ANG also participates in the process of wound healing and tissue regeneration in response to exogenous trauma by binding to actin and stimulating the tissue plasminogen activator. VEGF is a glycoprotein present in five isoforms resulting from alternative splicing of its mRNA: VEGF-A, -B, -C, -D and placental growth factor (PGF), of which VEGF-A is so far best described [22-26]. VEGF is produced by cells that primarily participate in wound healing, e.g. endothelial cells, fibroblasts, platelets, neutrophils and macrophages [27-30]. From the point of view of the development of venous ulcers, VEGF seems to be a particularly important factor responsible for the healing of the ulceration, due to its participation in many stages of angiogenesis, vasodilatation, basal membrane degradation, endothelial cell migration and their proliferation.

Therefore, it becomes necessary to determine which mechanisms govern the process of their development.

\section{Aim}

The aim of the study was to determine the serum concentration of MMP-1, MMP-9, TIMP-1, ANG and VEGF in patients suffering from venous leg ulcers as well as in the healthy control group in peripheral blood.

\section{Material and methods}

\section{Participants}

The study group consisted of 71 Caucasians (38 women and 33 men, at the average age of $72.99 \pm 4.82$ years), of which 39 were patients with leg ulcers, and 32 healthy volunteers (control). In all patients in the study group, the ulcer was a single lesion and was located near the medial malleolus. In addition, no participant in the study had a history of cancer in the interview, was a transplant recipient, received immunosuppressive therapy or suffered from other vascular disorders (coronary heart disease, etc.). All participants signed informed written consent before enrolment into the study. The study protocol was approved by the local bioethical committee and performed according to the Declaration of Helsinki principles.

\section{Methods}

To detect and evaluate concentrations of MMP-1, MMP-9, TIMP-1, VEGF and ANG enzyme-linked immunosorbent assay (ELISA) was employed. The following reagents (R\&D Systems Europe, Abingdon, UK) were used: DTM100 Human TIMP-1 Quantikine ELISA Kit, DMP900 Human MMP-9 (Total) Quantikine ELISA Kit, DMP100 Human Pro-MMP-1 Quantikine ELISA Kit, DANOO Human Angiogenin (ANG) Quantikine ELISA Kit, and DVEOO Human VEGF Quantikine ELISA Kit. All ELISA assays were performed using a quantitative sandwich immunoassay method. The concentration of each protein was assessed using ASSYS ExpertPlus microplate reader and the MikroWin2013 software. The following concentration units were used for each protein: MMP-1 
Table 1. Detailed results of MMP-1, MMP-9, TIMP-1 concentration in blood serum

\begin{tabular}{|c|c|c|c|c|c|c|}
\hline \multirow[t]{2}{*}{ Parameter } & \multicolumn{2}{|c|}{ MMP-1 [ng/ml] } & \multicolumn{2}{|c|}{ MMP-9 [ng/ml] } & \multicolumn{2}{|c|}{ TIMP-1 [ng/ml] } \\
\hline & Controls & Study group & Controls & Study group & Controls & Study group \\
\hline $25 \%$ percentile & 3.590 & 12.490 & 4.220 & 9.860 & 2.940 & 3.010 \\
\hline Median & 6.495 & 13.610 & 7.265 & 11.700 & 3.305 & 3.560 \\
\hline $75 \%$ percentile & 8.128 & 16.540 & 8.485 & 14.930 & 4.295 & 4.030 \\
\hline Mean & 6.084 & 14.160 & 6.773 & 12.450 & 3.557 & 3.580 \\
\hline Std. deviation & 2.508 & 2.980 & 2.414 & 3.854 & 1.035 & 0.7776 \\
\hline$P$ for comparison & \multicolumn{2}{|c|}{$<0.0001$} & \multicolumn{2}{|c|}{$<0.0001$} & \multicolumn{2}{|c|}{0.5872} \\
\hline
\end{tabular}

Table 2. Detailed results of VEGF and angiogenin concentration in blood serum

\begin{tabular}{lcccc}
\hline Parameter & \multicolumn{2}{c}{ VEGF [pg/ml] } & \multicolumn{2}{c}{ Angiogenin $[\mathrm{pg} / \mathrm{ml}]$} \\
\cline { 2 - 5 } & Controls & $\begin{array}{c}\text { Study } \\
\text { group }\end{array}$ & Controls & $\begin{array}{l}\text { Study } \\
\text { group }\end{array}$ \\
\hline 25\% percentile & 130.50 & 332.10 & 1045.00 & 1468.00 \\
\hline Median & 202.20 & 523.90 & 1147.00 & 1789.00 \\
\hline 75\% percentile & 317.10 & 679.80 & 1349.00 & 2081.00 \\
\hline Mean & 220.30 & 589.30 & 1229.00 & 1802.00 \\
\hline Std. deviation & 110.40 & 346.20 & 337.70 & 415.70 \\
\hline P for comparison & $<0.0001$ & & $<0.0001$ \\
\hline
\end{tabular}

[ng/ml], MMP-9 [ng/ml], TIMP-1 [ng/ml], angiogenin [pg/ml], and VEGF $[\mathrm{pg} / \mathrm{ml}]$.

\section{Statistical analysis}

Statistical analysis of the results was done using the Statistica 13 software (Statsoft, Tulsa, USA). To present the measures of the central tendency, the arithmetic mean and median were used. Standard deviation and the first/third quartiles were used to present the measures of dispersion. Statistical testing was preceded by an analysis of the distribution of variables using the Shapiro-Wilk test. The Student's t-test in Welch modification or the Mann-Whitney $U$ test was used to determine the significance of differences between the groups studied. The correlation assessment was based on correlation matrices and Pearson's correlation coefficient. The level of statistical significance for all analyses was $p<0.05$.

\section{Results}

Detailed results are shown in Tables 1, 2 and Figures 1 A-E. Mean MMP-1 and MMP-9 concentrations in the study group were $14.16 \pm 2.98$ and $12.45 \pm 3.85 \mathrm{ng} / \mathrm{ml}$, respectively, and in controls $6.08 \pm 2.51 \mathrm{ng} / \mathrm{ml}$ and 6.77 $\pm 2.41 \mathrm{ng} / \mathrm{ml}$, respectively and both differences were statistically significant $(p<0.001)$. There was no significant difference between the study and the control group in TIMP-1 concentration (Table 1). Mean VEGF and ANG con- centration in study group were $589.3 \pm 346.2 \mathrm{pg} / \mathrm{ml}$ and $1802.0 \pm 415.7 \mathrm{pg} / \mathrm{ml}$, respectively, and in controls 220.3 $\pm 110.4 \mathrm{pg} / \mathrm{ml}$ and $1229.0 \pm 337.7 \mathrm{pg} / \mathrm{ml}$, respectively and both differences were statistically significant $(p<0.001)$.

\section{Discussion}

The development of skin lesions during the course of $\mathrm{CVI}$ reflects the complex interaction between functional changes in the cardiovascular system, overexpression of proinflammatory cytokines and metalloproteinases and disturbance of cellular metabolism [3, 31]. It has been shown that the increased expression of metalloproteinases (MMP-1, MMP-2, MMP-8 and MMP-9) and the resulting extracellular matrix destruction is a phenomenon typical of chronic healing wounds [3, 32]. The activity of these proteins is regulated by TIMPs which activity plays a significant role in ulcer development [33]. In our study, the concentration of MMP-1 and MMP-9 in blood serum was significantly higher in patients with leg ulcers than in healthy controls, while TIMP-1 concentration was not significantly different between groups, which suggests that TIMP-1 is lacking its inhibitory activity in relation to MMP-1 and MMP-9. Nwomeh et al. [34] implied that increased activity of MMP- 8 and reduced TIMP-1 may be a phenomenon typical of non-healing ulcers [34]. Those results were confirmed by Amato et al. [3] who studied the activity of MMP-1 and MMP-8 in chronic leg ulcers on a group of 45 patients, which were divided into two subpopulations: the first consisted of patients with nonhealing ulcers, while the second consisted of patients in whom ulcers were responsive to treatment. In order to determine the concentrations of MMP-1 and MMP-8, they measured their activity in the serum fluid generated in the ulcer as well as in the tissues themselves. They showed that the level of MMP-1 and MMP-8, both in the tissue and in the serum, is significantly higher in the group of patients with non-healing ulcers, with the level of MMP-8 being significantly higher than that of MMP-1, regardless of the study group [3]. These results suggest that although the level of MMP-1 is significantly elevated in leg ulcers, the sole activity of MMP-8 may be an impor- 

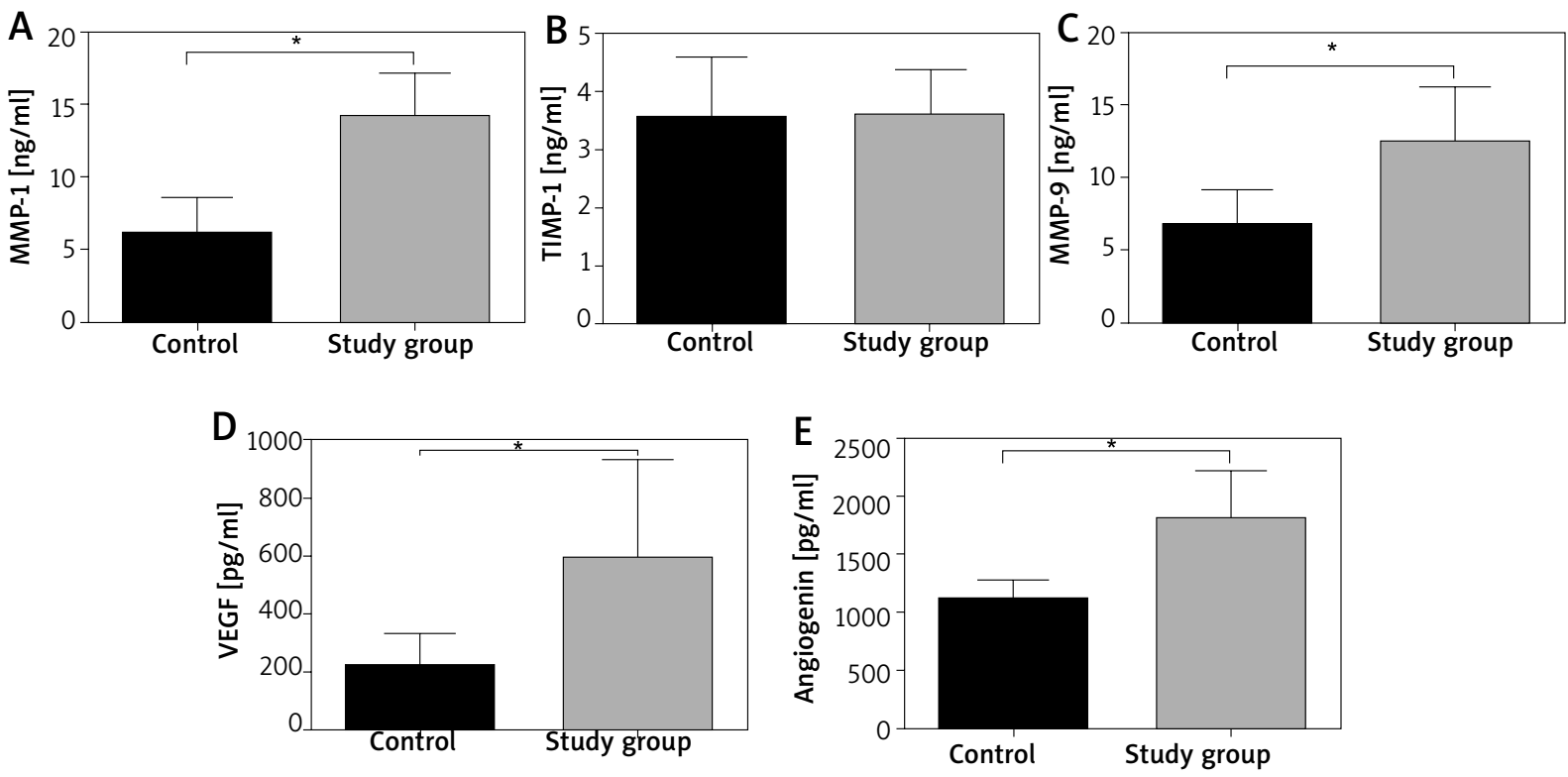

Figure 1. Detailed results

tant factor in prediction of ulcer healing, however these findings need further exploration.

Microvascular disturbances seem to precede the development of a full-sized ulcer. It has been proven that the decrease in microcirculation induces the expression of VEGF, which is one of the main regulators of angiogenesis. Studies conducted by Shoab et al. [35, 36] indicate that VEGF expression is elevated both in skin sections collected from the leg ulceration, correlating positively with the CEAP classification, as well as in the blood plasma of patients with CVI [36]. These observations are similar to those obtained in our study; mean VEGF concentration was significantly higher in patients with ulcerations than in the control group. Despite the possible therapeutic implications, the use of VEGF as a prognostic factor in the treatment of venous leg ulcers is still ambiguous. Shoab et al. [35] suggest that VEGF plasma concentration may be used in relation to clinical parameters of ulceration, but this is contradictory to the results obtained by Gohel et al. [37] who observed that VEGF concentration correlates with age of the patient, however, does not correlate with the size of the ulcer.

Angiogenesis, stimulated mainly by angiogenin is an important stage in the process of wound development and healing. In our study, the mean serum concentration of angiogenin in the study group was significantly higher than in the control group. It is difficult to compare these results in the context of other studies because, to the best of our knowledge, there is lack of studies regarding serum angiogenin concentration in patients with leg ulcers. Pan et al. [38] studied the expression of angiogenin in serum from burn blister fluid (BBF). The blockage of angiogenin activity in BBF was associated with a lower percentage of endothelial cell proliferation and the formation of new vessels in vivo; similarly, increased angiogenesis was observed with an increased expression of angiogenin [38]. The potential involvement of angiogenin in wound healing was demonstrated by Ma et al. [39] in a study using vacuum therapy in a murine model. They have shown that vacuum therapy increases the expression of angiogenin, leading to stabilization of the microvascular environment by recruitment of pericytes.

\section{Conclusions}

Obtained results suggest that MMP-1 and MMP-9 are participating in development of venous leg ulcers, however the exact mechanism still needs further exploration. Lack of significant differences in the concentration of TIMP-1 between the control and the study group confirms that proteolysis is a hallmark of CVI, but increased concentration of VEGF and angiogenin in the study group compared to the control group shows that angiogenesis occurs simultaneously with ECM remodelling.

\section{Acknowledgments}

The study was founded by the Medical University of Lodz, project no. 503/5-064-01/503-01.

\section{Conflict of interest}

The authors declare no conflict of interest. 


\section{References}

1. Curyło M, Cienkosz K, Mikos M, Czerw A. Epidemiology and diagnostics of venous disease in Poland Epidemiologia i diagnostyka choroby żylnej w Polsce. J Educ Heal Sport 2017; 7: 49-57.

2. Dudzisz-Śledź M, Śledź A. Crural ulceriations. Med Rodz 2006; 2: 41-4.

3. Amato B, Coretti G, Compagna R, et al. Role of matrix metalloproteinases in non-healing venous ulcers. Int Wound I 2015; 12: 641-5.

4. Serra R, Buffone G, Falcone D, et al. Chronic venous leg ulcers are associated with high levels of metalloproteinases- 9 and neutrophil gelatinase-associated lipocalin. Wound Repair Regen 2013; 21: 395-401.

5. Clark I, Swingler T, Sampieri C, Edwards D. The regulation of matrix metalloproteinases and their inhibitors. Int J Biochem Cell Biol 2008; 40: 1362-78.

6. Nagase H, Woessner JF. Matrix metalloproteinases. J Biol Chem 1999; 274: 21491-4.

7. Murphy G. Riding the metalloproteinase roller coaster. J Biol Chem 2017; 292: 7708-18.

8. Ziober BL, Turner MA, Palefsky JM, et al. Type I collagen degradation by invasive oral squamous cell carcinoma. Oral Oncol 2000; 36: 365-72.

9. Kerkelä E, Saarialho-Kere U. Matrix metalloproteinases in tumor progression: focus on basal and squamous cell skin cancer. Exp Dermatol 2003; 12: 109-25.

10. Muller M, Trocme C, Lardy B, et al. Matrix metalloproteinases and diabetic foot ulcers: the ratio of MMP-1 to TIMP-1 is a predictor of wound healing. Diabet Med 2008; 25: 419-26.

11. Murray GI, Duncan ME, O'Neil P, et al. Matrix metalloproteinase-1 is associated with poor prognosis in colorectal cancer. Nat Med 1996; 2: 461-2.

12. Murray GI, Duncan ME, O’Neil P, et al. Matrix metalloproteinase- 1 is associated with poor prognosis in oesophageal cancer. J Pathol 1998; 185: 256-61.

13. Rodriguez Faba O, Palou-Redorta J, Fernández-Gómez JM, et al. Matrix metalloproteinases and bladder cancer: what is new? ISRN Urol 2012; 2012: 581539.

14. Gene: MMP9 (ENSG00000100985) - Summary - Homo sapiens - Ensembl genome browser 89, (n.d.). http:// may2017.archive.ensembl.org/Homo sapiens/Gene/Su mmary? $\mathrm{db}=$ core; $g=$ ENSG00000100985; $r=20: 46008908$ 46016561; t=ENST00000372330 (accessed February 2, 2019).

15. Reiss MJ, Han YP, Garcia E, et al. Matrix metalloproteinase- 9 delays wound healing in a murine wound model. Surgery 2010; 147: 295-302.

16. Jindatanmanusan P, Luanraksa S, Boonsiri T, et al. Wound fluid matrix metalloproteinase- 9 as a potential predictive marker for the poor healing outcome in diabetic foot ulcers. Patholog Res Int 2018; 2018: 1631325.

17. Śliwowska I, Kopczyński Z. Matrix metalloproteinases - biochemical characteristics and clinical value determination in breast cancer patients, Contemp Oncol 2005; 9: 327-35.

18. Ulrich D, Ulrich F, Unglaub F, et al. Matrix metalloproteinases and tissue inhibitors of metalloproteinases in patients with different types of scars and keloids. J Plast Reconstr Aesthetic Surg 2010; 63: 1015-21.

19. Caley MP, Martins VLC, O'Toole EA. Metalloproteinases and wound healing. Adv Wound Care 2015; 4: 225-34.

20. Fett JW, Strydom DJ, Lobb RR, et al. Isolation and characterization of angiogenin, an angiogenic protein from human carcinoma cells. Biochemistry 1985; 24: 5480-6.
21. Yu D, Cai Y, Zhou W, et al. The potential of angiogenin as a serum biomarker for diseases: systematic review and meta-analysis. Dis Markers 2018; 2018: 1984718.

22. Xiao Z, Li S, Yu Y, et al. VEGF-A regulates sFlt-1 production in trophoblasts through both Flt-1 and KDR receptors. Mol Cell Biochem 2018; 449 (Suppl A): 1-8.

23. Arjunan P, Lin X, Tang Z, et al. VEGF-B is a potent antioxidant. Proc Natl Acad Sci 2018; 115: 10351-6.

24. Jiang L, Liu M, Cai X, et al. Serum vascular endothelial growth factor $C$ levels predict lymph node metastasis and prognosis of patients with gallbladder cancer. Oncol Lett 2018; 16: 6065-70.

25. Berntsson J, Smith JG, Johnson LSB, et al. Increased vascular endothelial growth factor $D$ is associated with atrial fibrillation and ischaemic stroke. Heart 2018; heartjnl-2018-313684. doi:10.1136/heartjnl-2018-313684.

26. Parchem JG, Kanasaki K, Kanasaki M, et al. Loss of placental growth factor ameliorates maternal hypertension and preeclampsia in mice. J Clin Invest 2018; 128: 5008-17.

27. Banks RE, Forbes MA, Kinsey SE, et al. Release of the angiogenic cytokine vascular endothelial growth factor (VEGF) from platelets: significance for VEGF measurements and cancer biology. Br J Cancer 1998; 77: 956-64.

28. Nissen NN, Polverini PJ, Koch AE, et al. Vascular endothelial growth factor mediates angiogenic activity during the proliferative phase of wound healing. Am J Pathol 1998; 152: 1445-52.

29. Gaudry M, Brégerie O, Andrieu V, et al. Intracellular pool of vascular endothelial growth factor in human neutrophils. Blood 1997; 90: 4153-61.

30. Berse B, Brown LF, Van de Water L, et al. Vascular permeability factor (vascular endothelial growth factor) gene is expressed differentially in normal tissues, macrophages, and tumors. Mol Biol Cell 1992; 3: 211-20.

31. Raffetto JD. Pathophysiology of chronic venous disease and venous ulcers. Surg Clin North Am 2018; 98: 337-47.

32. Bao P, Kodra A, Tomic-Canic M, et al. The role of vascular endothelial growth factor in wound healing. I Surg Res 2009; 153: 347-58.

33. Brew K, Nagase H. The tissue inhibitors of metalloproteinases (TIMPs): an ancient family with structural and functional diversity. Biochim Biophys Acta 2010; 1803: 55-71.

34. Nwomeh BC, Liang HX, Cohen IK, Yager DR. MMP-8 is the predominant collagenase in healing wounds and nonhealing ulcers. J Surg Res 1999; 81: 189-95.

35. Shoab SS, Scurr JH, Coleridge-Smith PD. Plasma VEGF as a marker of therapy in patients with chronic venous disease treated with oral micronised flavonoid fraction - a pilot study. Eur J Vasc Endovasc Surg 1999; 18: 334-8.

36. Shoab SS, Scurr JH, Coleridge-Smith PD. Increased plasma vascular endothelial growth factor among patients with chronic venous disease. J Vasc Surg 1998; 28: 535-40.

37. Gohel MS, Windhaber RAJ, Tarlton JF, et al. The relationship between cytokine concentrations and wound healing in chronic venous ulceration. J Vasc Surg 2008; 48: 1272-7.

38. Pan SC, Wu LW, Chen CL, et al. Angiogenin expression in burn blister fluid: implications for its role in burn wound neovascularization. Wound Repair Regen 2012; 20: 731-9.

39. Ma Z, Jian C, Li Z, et al. Negative pressure wound therapy improves the quantity and quality of wound angiogenesis in diabetic rats by regulating the Ang/Tie-2 system, 2016. www. ijcem.com/ (accessed February 3, 2019). 